\title{
A quantitative analysis of mindfulness practice as self-care for social workers in an urban setting
}

\author{
Matthew T. Diner, PhD, LCSW ${ }^{1}$ \\ 1 School of Health Sciences and Professional Programs, CUNY York College, New York, United States
}

Received 29 March 2020

Accepted for publication 26 May 2020

Published 30 June 2020

\begin{abstract}
This study examines the relationship between mindfulness and secondary traumatic stress (STS) amongst licensed social workers in New York City. The research that was conducted was a quantitative analysis. Participants consisted of 154 social workers that were employed in a variety of agency based or private practice settings. Participants were asked to complete an electronic survey that included: (1) a questionnaire of professional characteristics and demographic information; (2) Cognitive and Affective Mindfulness Scale - Revised (CAMS-R); (3) Minnesota Satisfaction Questionnaire (MSQ); (3) Secondary Traumatic Stress Scale (STSS). The data was analyzed by the use of SPSS Version 22. Multivariate linear regression analyses revealed that higher level of mindfulness is related to increased job satisfaction $(B=1.13, \mathrm{SE}=.09, \beta=.73$, $p<.001)$ and lower STS for social workers $(B=-.66, \mathrm{SE}=.11, \beta=-.49, p<.001)$.
\end{abstract}

Keywords: self-care; secondary traumatic stress; burnout; mindfulness; meditation

\section{Introduction}

The social work profession is characterized as one of the most stressful and emotionally demanding disciplines (Simpson and Starkey, 2006). Many professionals work diligently to help their clients find meaning in their traumatic experiences and reduce the negative consequences of their subjective experience. However, this process often comes at a considerable cost to the worker (Newell and MacNeil, 2010). Literature has long documented that secondary traumatic stress (STS) is prevalent among frontline care workers, such as, emergency room nurses, palliative care workers, crisis workers and psychotherapists, but there is a dearth of literature studying the prevalence of STS of generalist social work practitioners (Abendroth and Flannery, 2006; Bride, 2007; Cornille and Meyers, 1999; DominguezGomez and Rutledge, 2009).

For social workers, exposure to STS places the worker at risk for burnout and psychological distress that compromises service outcomes and worker effectiveness (Bride, 2007). Taking this into account, it is critical to increase the understanding of effective self-care techniques to counter the effects of STS. This study examined the relationship between mindfulness and STS amongst social workers. The type of study conducted was a correlational design, based on social workers' self-report of conditions of work and their experience of STS. This study also investigated the impact of working conditions on workers and whether meditation practice leads to increased levels of mindfulness to ameliorate symptoms associated with STS both for the sustainment of the profession and to ensure maximum capacity and quality service to clients.

\subsection{Importance of increased understanding}

In the United States alone, the lifetime prevalence exposure to traumatic events in the general public is between $40 \%$ and $81 \%$, with $60.7 \%$ of males and $51.2 \%$ of females reporting exposure to one or more traumas and $19.7 \%$ of males and $11.4 \%$ of females reporting exposure to three or more events (Breslau et al., 1997; Bride, 2007; Stein et al.1997; Va, 2001). Exposure of the general population to traumatic events is relatively high; perhaps higher among those seeking social work support. For instance, $84 \%$ of 
psychiatric inpatients identified at least one traumatic event category with symptoms consistent with PTSD (Escalona et al., 1997). Similarly, psychiatric outpatients also demonstrated traumatic experiences with symptoms consistent with PTSD. Studies identified that between $82 \%$ and $94 \%$ of the outpatient mental health population have been exposed to at least one lifetime trauma and $31 \%$ and $42 \%$ identified with criteria consistent with PTSD (Davidson and Smith, 1990; Switzer et al., 1999). These rates are likely to be greater higher in countries that are impacted by terrorism, war, natural disaster and other violent or traumatic environments.

In recent decades, social work has increasingly provided services for clients with traumatic memory and traumatic symptomology (Bober and Regehr, 2006; Collins, 2003). With this in mind, social workers are often at risk for developing work-related psychological distress, such as increased anxiety, depression, mental fatigue and strained interpersonal relationships (Collins, 2003; Tyssen et al., 2001). Such distress places workers at risk for developing STS, which is regarded as an "occupational hazard" in the workforce (Bride, 2007). Seeking more information on the prevalence of STS and methods to improve self-care to protect the worker from STS is consistent with the profession's commitment to support vulnerable populations. Social workers must be able to cope themselves in order to support others competently and effectively.

The symptoms of STS are nearly identical to those of PTSD (Figley, 2002). STS is defined as the emotional duress that ensues when an individual hears about traumatic experiences of another. Accordingly, those affected find themselves experiencing symptoms of intrusion, avoidance, and arousal (Figley, 2002; Mann, 2004; Pearlman and Saakvitne, 1995). The practice of self-care has been noted in research to serve to buffer the effects of symptoms associated with STS (Newell and MacNeil, 2010). Over the last several decades, meditation has been identified as one of the most researched psychotherapeutic methods that may serve as an effective intervention for stress management and symptom reduction (Astin, 1997; Kabat-Zinn et al., 1992; Shapiro and Walsh, 2003). However, despite the extensive literature about STS among frontline care workers, there is still a dearth of evidence regarding STS and social work professionals. In order for the worker to reduce the symptoms of STS, advancing the knowledge of effective self-care techniques is imperative and may be viewed as a mechanism to enhance the values of service and competence.

Figley (2002, pp. 1433-1434) states that "to see the world as our clients see it enables us to calibrate our services to fit them and to adjust our services to fit how they are responding." Delivering effective social work practice requires empathy, which is paramount to the therapeutic relationship (Lambert and Barley, 2001). Without empathy, there would be no secondary traumatic stress, as the worker would be indifferent to the client's suffering (Figley, 1995).

Empathy requires that the social worker understands the service user's emotional pain and suffering. Figley (2002) asserts that during this process, the worker bears the suffering as well. Figley (1993, p. 7) states that STS is "the natural consequent behaviors and emotions resulting from knowing about a traumatizing event experienced by a significant other-the stress resulting from helping or wanting to help a traumatized or suffering person". Research supports that STS is prevalent in the workplace when the stress of bearing one's suffering is coupled with a lack of emotional support and poor self-care (Radley and Figley, 2007).

Social workers who suffer from STS, experience symptoms that permeate and impact all areas of functioning, causing them to be physically, mentally and spiritually disabled (Showalter, 2010). STS symptoms influence behavior and cognition and have damaging effects on the worker's effectiveness and success by reducing their capacity for attention, empathy, concentration and decision-making (Figley, 2002). Further, in their personal lives, workers with STS may often display signs of depression, irritability, interpersonal withdrawal and somatic symptoms (Figley, 2002).

Supervision is identified as the profession's primary response to counter the stressful nature of social work practice. Supervision also serves to aid in reducing the sense of isolation and increase feelings of efficacy (Bober and Regehr, 2006). Other responses to work-related stress in social work are bio-behavioral coping strategies, such as physical health, spiritual practice, balanced nutrition, adequate sleep, exercise, or recreation (Newell and MacNeil, 2010).

As the growing body of literature suggests, more effective ways of preventing and ameliorating the effects of STS among social work professionals need to be explored. Meditation, one of the most widely researched therapeutic interventions to enhance well-being, may offer a means to mitigate the effects of STS. Meditation may serve as a medium to counteract STS and cultivate compassion for self and others (Walsh and Shapiro, 2006) and benefits the practitioner by aiding in the development of empathy, 
attention, equanimity and presence (Walsh and Shapiro, 2006).

\section{Literature review}

\subsection{STS amongst social workers}

In a 30 year old study, Guy, Polestra and Stark (1989) reported that $74.3 \% \quad(n=318)$ psychologists experienced personal distress over a three year period, while $36.7 \%$ expressed that it greatly impaired the quality of service they were able to provide for their clients, and $4.6 \%$ admittedly expressed that it resulted in inadequate treatment.

Meldrum, King and Spooner (2002) found that 27\% of social work professionals that work with traumatized individuals experience extreme distress from their work. The study reported that $54.8 \%$ were distressed at the time of the study and $35.1 \%$ were emotionally drained (Meldrum et al., 2002). Similarly, Sprang, Clark and Whitt-Woolsey (2007) reported that mental health workers $(n=1,121)$ of a rural southern state in the United States experienced STS more frequently than their counterparts that received specialized training in trauma. The study found that female gender, younger age, lack of education and/or experience in clinical work, and a higher caseload of clients diagnosed with PTSD correlated with higher levels of STS.

Rudolph, Stamm and Stamm (1997) studied both individual and organisational variables to examine potential risks and mediating factors in the development of STS. The method included 113 females and 66 males from Alaska Public Health Nurse Annual Convention, American Red Cross, InterPsych and University of Alaska Anchorage. $37 \%$ $(n=64)$ of the participants were at high risk for compassion fatigue and $54 \%(n=97)$ at high risk for burnout. Post hoc analyses found that social workers with an MSW were at a significantly higher level for developing compassion fatigue (CF) and burnout than the group as a whole. Likewise, social workers with a bachelor level-education were at a lower risk for developing $\mathrm{CF}$ and burnout than the group as a whole (Rudolph et al., 1997).

\subsection{Meditation}

Historically, meditation originated over 3,000 years ago in India, and is viewed as a vehicle to attain higher levels of concentration and transpersonal levels of development (Shapiro and Walsh, 2003). In the past two decades, meditation has gained popularity in psychological and medical literature as an effective clinical intervention to reduce stress and improve certain medical conditions (Shapiro et al., 2006). In particular, the term mindfulness is currently fashionable in literature to describe meditation practice. Mindfulness describes, "the awareness that emerges by way of paying attention on purpose, in the present moment, and nonjudgmentally to unfolding of experience moment by moment" (Jon Kabat-Zinn, 2006, p. 145). Mindfulness meditation is a process by which the meditator becomes aware of mental activity as an observer, without making an effort to modify it (Boyce, 2011).

Prior to the emergence of meditative practice in health, meditative practice was studied in medical research. Herbert Benson, an early researcher of meditation, pioneered studies of meditation that studied the dramatic effects of meditation on the human body. Benson termed these effects as the Relaxation Response (RR) (Benson, 1975). Benson's RR technique is to silently chant a one-word mantra, such as, "one" or "love" for 10 minutes. Benson's research of RR concluded it as a wakeful hypo metabolic state that causes oxygen consumption and blood pressure to drop significantly (Benson, 1975; Park et al., 2013). Benson's research showed that when RR was practiced regularly, symptoms such as pain, irregular heartbeats, hot flashes due to menopause, insomnia, and infertility are improved or eliminated (Benson, 1975).

In 1979, meditation practice gained recognition as a legitimate intervention in healthcare and psychotherapy. Kabat-Zinn's Mindfulness Based Stress Reduction (MBSR) teaches meditation to help accept pain (Turner, 2009). MBSR is an 8-week course for the reduction of chronic pain and stress (Turner, 2009). Medical research has documented MBSR effectiveness to improve the immune system in response to a flu vaccine, the improved clearing of psoriasis, improve innate immunity and anxiety disorders (Davidson, et al., 2003; Fang et al., 2010; Kabat-Zinn et al., 1992, p. 199; Kabat-Zinn et al., 1998).

Within the last 15 years, meditation has quickly moved into the mainstream of behavioral medicine, psychotherapy and counseling (Christopher and Maris, 2010). Within these fields, meditation is gaining attention as a viable form of self-care. Literature has long documented and recognized the importance of providing clinicians with the tools of self-care early in their careers, even while they are being trained (Baker, 2003; Christopher and Maris, 2010; Kuyken et al., 2003; Weiss, 2004). Recent extensive research on stress management in the education of healthcare has demonstrated that meditation-based interventions promise to lower levels of anxiety and depression and offer greater capacity for empathy and improved immunological functioning (Shapiro, Shapiro and Schwartz, 2000). Educators have begun to correlate the stressors that mental health professionals 
experience with the benefits of meditation as a viable means of self-care (Shapiro et al., 2006).In addition to meditation's role as a means to self-care, it also serves as a clinical intervention, and may have applications to increase both the well-being and effective practice of mental health workers (May and O'Donovan, 2007).

This study contributes to the existing research on the value of meditation practice among social work professionals and its contribution to their professional health and wellbeing. Secondarily, this study contributes to the growing body of literature on self-care practices among social work professionals and the value of the practices in terms of worker wellbeing for the prevention of STS and to keep the workforce providing quality service. By increasing our understanding of the relationship between these two variables, we are potentially increasing our professional competency and service.

\section{Methodology}

\subsection{Research design}

This research consisted of a correlational design, based on social workers' self-report of conditions of work and their experience of STS. The purpose of a correlational design allows the researcher to examine a phenomenon by taking a cross section of it at one point in time in order to show the plausibility of a causal relationship (Rubin, 1999). The advantage of a correlational design is to determine whether or not two variables are correlated; this illustrates whether an increase or decrease in one variable corresponds to an increase or decrease in the other variable (Privitera, 2013). The statistical package of SPSS Version 22 was used to analyze the data. The data was analyzed with bivariate and multivariate regression analyses (Tabachnick and Fidell, 2012).

\subsection{Context of study}

This study used convenience sampling of a diverse population of social workers in New York State (Privitera, 2013). Participants were recruited from two community based non-profit organizations that offered numerous mental health services. In addition, the researcher used convenience sampling by recommending that survey respondents forward the survey link to others. The surveys were fully anonymized.

An invitation email was sent with a brief description of the study and the online survey URL, which directed to the online consent form. The online consent form contained a detailed explanation of the study and the names and contact information of affiliated Yeshiva research study personnel. Participants were prohibited from completing the survey more than once via a feature of SurveyMonkey, in which the URL can set a limit of allowing only one response per computer by placing a cookie on the individual's browser. The researcher was not able to access any identifying information provided by the participants. This study was approved by the Institutional Review Board of Yeshiva University.

\subsection{Data and participants}

As a requisite for this study, only Licensed Master Social Workers (LMSW) and Licensed Clinical Social Workers (LCSW) were recruited; these licensures are considered the fundamental requisite to practice social work in New York State, the difference in acronym denotes a generalist and clinical license respectively. In addition, another distinction between these licenses is that the generalist license (LMSW) is acquired upon graduation with an MSW and successful completion of a national exam while the clinical license takes at least three years post-graduation of full-time clinical social work practice and supervision with a qualified supervisor and passing a national, clinical exam.

A power analysis indicated that 150 study participants would provide sufficient statistical power to detect a medium size effect between the independent and dependent variables within a multiple linear regression model using four predictors. The sample, thus, consisted of 154 respondents and was representative of licensed social workers working in a wide diversity of fields, thereby contributing to the study's generalizability.

\subsection{Measures}

3.4.1 Secondary Traumatic Stress Scale (STSS). STSS is a 17-item, self-report, Likert-style instrument designed to assess the frequency of intrusion, avoidance and arousal symptoms (predominate features of PTSD criteria American Psychiatric Association, 2000) associated with STS. STSS has demonstrated reliability, convergent and discriminant validity, and factorial validity (Bride, 2004).

Respondents are asked to state how far they relate to the 17 statements in the tool, and within the last seven days. The responses are recorded on a 1-5 Likert-style scale (1=never and $5=$ very often); the higher the score, the greater the amount of STS and conversely. For the purposes of this study, the instructions have been modified to read the impact of their "work" instead of "work with traumatized clients". 


\subsubsection{Cognitive and Affective Mindfulness Scale-} Revised (CAMS-R). Mindfulness is both an independent and dependent variable in this study. To measure mindfulness, the Cognitive and Affective Mindfulness Scale - Revised (CAMS-R) was used. The CAMS-R was developed by Feldman et al. (2007) and is used as a multidimensional measure of mindfulness. The CAMS-R is a 12item Likert style measure and applicable with a wide variety of samples. The instrument measures four domains of mindfulness: the ability to regulate attention, an orientation to present or immediate experiences, awareness of experience, and an attitude of acceptance or non-judgment towards experience. The CAMS- $\mathrm{R}$ has demonstrated acceptable internal consistency and evidence of convergent and discriminant validity with concurrent measures of mindfulness (Feldman et al., 2007). The higher one scores on the CAMS-R the higher it reflects one's level of mindfulness.

\subsubsection{Minnesota Satisfaction Questionnaire}

(MSQ). Job satisfaction is both an independent and dependent variable in the study. The Minnesota Satisfaction Questionnaire (MSQ) short form was created and developed by Weiss et al. (1967) to measure overall job satisfaction. MSQ has demonstrated acceptable reliability and validity. The instrument elicits responses that are indicative of whether workers like or dislike their job. The MSQ short form consists of 20 statements related to the intrinsic and extrinsic reinforcers of the work environment (May and O'Donovan, 2007; Weiss et al., 1967).

\subsubsection{Demographics and Professional Characteristics}

Questionnaire. The Demographics and Professional Characteristics questions address gender, salary, years in practice, level of education, employment status, major area of specialization, composition of workload, work setting and type of client (i.e. children, adolescents, adults). This section also inquires if the participant practices yoga/meditation and if so, for how long (in months) and how often (per week).

\subsection{Data analysis}

Data analysis was conducted in three phases. First, all data was analyzed descriptively via univariate analysis. Frequency distributions and percentages were obtained from the questionnaire to describe the characteristics of the participants in the study. Second, the relationship between the dependent variable STS and the independent variables (mindfulness, job-satisfaction, education level, years of social work practice, direct service versus administration and percentage of trauma related work) were examined using bivariate analysis. Third, a multivariate regression analysis was used to model scores reflecting the dependent variables as a function of all predictor variables included in the multivariate model. Prior to data analysis, an examination of test assumptions indicated a satisfactory level of homoscedasticity, linearity and normality. Further, the data was tested to indicate that multicollinearity does not present a significant problem (see Table 1).

The hypotheses using the test of Pearson productmoment correlation coefficient were used to measure the strength of relationship between two scales or interval/ratio variables; independent $\mathrm{T}$-tests were used when the independent variable was a dichotomous variable and the dependent variable is a scale or interval level variable. Oneway analysis of variance was used when the independent variable has three or more nominal or grouped ordinal categories and the dependent variable was a scale or interval level variable (Field, 2013). Predictor variables associated with the dependent variable at a statistically significant level $(p<.05)$ were entered in the final multivariate model.

Table 1. Hypotheses, variables and corresponding analyses

\begin{tabular}{|l|l|l|}
\hline \multicolumn{1}{|c|}{ Hypothesis } & \multicolumn{1}{|c|}{ Variable Use } & \multicolumn{1}{|c|}{ Analysis } \\
\hline H1 The higher the level of mindfulness, the higher the level of job satisfaction. & $\begin{array}{l}\text { IV*: CAMS-R } \\
\text { DV**: MSQ }\end{array}$ & $\begin{array}{l}\text { Pearson } \\
\text { correlation }\end{array}$ \\
\hline $\begin{array}{l}\text { H1a There is a positive correlation between the length of time practicing meditation and the } \\
\text { workers' level of mindfulness. The longer one practices meditation, the higher the level of } \\
\text { mindfulness. }\end{array}$ & $\begin{array}{l}\text { IV: Ratio } \\
\text { DV: CAMS-R }\end{array}$ & $\begin{array}{l}\text { Pearson } \\
\text { correlation }\end{array}$ \\
\hline $\begin{array}{l}\text { H1b There is a positive correlation between the length of time practicing yoga and the workers' } \\
\text { level of mindfulness. The longer one practices yoga, the higher the level of mindfulness. }\end{array}$ & $\begin{array}{l}\text { IV: Ratio } \\
\text { DV: CAMS-R }\end{array}$ & $\begin{array}{l}\text { Pearson } \\
\text { correlation }\end{array}$ \\
\hline H2 The greater the workers' level of mindfulness, the lower the level of STS. & $\begin{array}{l}\text { IV: CAMS-R } \\
\text { DV: STSS }\end{array}$ & $\begin{array}{l}\text { Pearson } \\
\text { correlation }\end{array}$ \\
\hline
\end{tabular}

\footnotetext{
$*$ Independent Variable $=$ IV $* *$ Dependent Variable $=\mathrm{DV}$
} 


\section{Results}

\subsection{Descriptive analyses}

Table 2 presents a descriptive analysis of the categorical study variables. The sample was mostly female $(\mathrm{n}=113$; $73.4 \%)$, between the ages of 26-50 ( $\mathrm{n}=128 ; 83.1 \%)$, White/Caucasian $(\mathrm{n}=48 ; 31.2 \%)$, people of color $(\mathrm{n}=106$; $68.8 \%)$ and married/living with partner $(\mathrm{n}=69 ; 44.8 \%)$. About one-third of participants reported their year of graduation as 2011-2016 $(\mathrm{n}=56 ; 36.4 \%)$. Over three-quarters of the sample reported their highest level of education as MSW ( $\mathrm{n}=123 ; 79.9 \%)$.

Almost three-quarters of the 36 members of the sample with data reported extra hours worked per week as $0-5$ $(\mathrm{n}=26 ; 72.2 \%)$. The mid-point for reported salary range was $\$ 46,000-\$ 55,000$ annually $(n=37 ; 24.0 \%)$. Most participants reported an agency work setting $(\mathrm{n}=114 ; 74.0 \%)$. The most commonly reported agency of work was mental health $(n=47 ; 30.5 \%)$ and type of clients was adults $(n=62 ; 40.3 \%)$. A minority of the sample reported no trauma work $(n=25$; 16.2\%). The majority of the sample reported practicing selfcare $(n=107 ; 69.5 \%)$ and yoga $(n=60 ; 39.0 \%)$, while less than half reported practicing meditation $(\mathrm{n}=62 ; 40.3 \%)$.

Table 3 presents a descriptive analysis of continuous study variables. Data indicated that the average study participant practiced yoga $(n=47)$ for 25.17 months $(\mathrm{SD}=17.98, \mathrm{MIN} / \mathrm{MAX}=4-73)$ and meditation $(n=34)$ for 27.98 months ( $\mathrm{SD}=21.6$; MIN/MAX=2-120). Of the full sample of 154 study participants, the average score for the mindfulness scale was 2.88 ( $\mathrm{SD}=.71 ; \mathrm{MIN} / \mathrm{MAX}=1.00$ 4.00), for the MSQ was 3.47 ( $\mathrm{SD}=1.10$; MIN/MAX=1.005.00) and STSS was 1.93 (SD=.96; MIN/MAX=1.00-4.88).

\subsection{Hypothesis and model testing}

\subsubsection{Hypothesis 1: The higher the level of mindfulness,} the higher the level of job satisfaction. Table 4 shows that at the bivariate level, hypothesis 1 is supported as mindfulness was significantly associated with job satisfaction at a statistically significant level $[\mathrm{r}(152)=.80$, $\mathrm{p}<.01]$. Table 5 indicates that at the bivariate level, the level of job satisfaction was also significantly related to age $[\mathrm{F}(4$, $149)=3.55, \mathrm{p}<.01]$, yoga practice $[\mathrm{t}(150.49)=6.88, \mathrm{p}<.001]$ and meditation practice $[\mathrm{t}(149.14)=8.12, \mathrm{p}<.001]$. Due to a high level of multicollinearity between yoga and meditation practice, only practice yoga was included in the final multivariate model along with the variable age. Bivariate analysis also indicated no statistically significant relationships between job satisfactions with gender $[\mathrm{t}(152)=.51, \mathrm{p}=.61]$, race $[\mathrm{F}(5,148)=3.41, \mathrm{p}<.01]$ (individual mean scores did not differ significantly), education level $[\mathrm{t}(60.48)=-1.89, \mathrm{p}=.06]$ and perceived trauma work $[\mathrm{F}(4$, 149) $=2.05, \mathrm{p}=.09]$.

Table 6 indicates that hypothesis 1 was also supported at the multivariate level. Specifically, Table 6 presents a multiple linear regression model, which achieved a level of statistical significance $\left[\mathrm{F}(6,147)=50.35, \mathrm{p}<.001, \mathrm{R}^{2}=.67\right.$, Adjusted $\left.\mathrm{R}^{2}=.66\right]$. In terms of individual predictors, data indicated that in reference to study participants' age, 51 and over, those between the ages $26-30[\mathrm{~B}=.41, \mathrm{SE}=.27, \beta=.17$, $\mathrm{p}<, 05]$ and 41-50 [B=.51, $\mathrm{SE}=.19, \beta=.20, \mathrm{p}<.01]$ evidenced significantly higher job satisfaction scores. Findings also indicated that those who practice yoga evidenced significantly higher job satisfaction scores $[\mathrm{B}=.26, \mathrm{SE}=.12$, $\beta=.12, p<.05]$. Lastly, mindfulness was also related to job satisfaction in the context of the full multivariate model $[\mathrm{B}=1.13, \mathrm{SE}=.09, \beta=.73, \mathrm{p}<.001]$.

\subsubsection{Hypothesis 2: The greater the workers' level of} mindfulness, the lower the level of STS. Table 4 indicates that at the bivariate level hypothesis 2 is supported as mindfulness was significantly associated with STS scores at a statistically significant level $[r(152)=-.54, p<.01]$. Germane to hypothesis 2, table 7 indicates that at the bivariate level, STS scores were also significantly related to age $[F(4,149)=3.76, p<.01]$, yoga practice $[t(144.78)=-3.60$, $p<.001]$ and meditation practice [t(142.35)=-4.72, $\mathrm{p}<.001]$. Due to a high level of multicollinearity between yoga and meditation practice, only practice yoga was included in the final multivariate model along with the variable age. Bivariate analysis also indicated no statistically significant relationships between STS with gender $[t(152)=-.80, p=.41]$, race $[F(5,148)=1.06, p=.38]$, education level $[t(61.88)=.61$, $p=.55]$ and percent trauma work $[F(4,149)=3.76, p<.01]$ (individual mean scores did not differ significantly).

Table 8 indicates that hypothesis 2 was also supported at the multivariate level. A multiple linear regression model achieved a level of statistical significance $[F(6,147)=11.87$, $p<.001, \mathrm{R}^{2}=.33$, Adjusted $\mathrm{R}^{2}=.30$ ]. Age was not significantly related to STSS scores at the multivariate level. Findings also indicated that yoga practice was not associated with STSS scores in the full model $[B=-.04, \mathrm{SE}=.15, \beta=-.02, p=.80]$. However, data did indicate that higher mindfulness scores were related to lower STSS scores in the context of the full multivariate model $[B=-.66, \mathrm{SE}=.11, \beta=-.49, p<.001]$. 
Table 2. Descriptive analysis of categorical study variables $(n=154)$

\begin{tabular}{|c|c|c|}
\hline Variable & $n$ & $\%$ \\
\hline \multicolumn{3}{|l|}{ Gender } \\
\hline Male & 41 & 26.6 \\
\hline Female & 113 & 73.4 \\
\hline \multicolumn{3}{|l|}{ Age } \\
\hline $20-25$ & 9 & 5.8 \\
\hline $26-30$ & 43 & 27.9 \\
\hline $31-40$ & 45 & 29.2 \\
\hline $41-50$ & 40 & 26.0 \\
\hline $51-60$ & 15 & 9.7 \\
\hline 61 or over & 2 & 1.3 \\
\hline \multicolumn{3}{|l|}{ Race } \\
\hline Caucasian & 48 & 31.2 \\
\hline Black/African American & 22 & 14.3 \\
\hline Hispanic/Latino & 42 & 27.3 \\
\hline West Indian/Caribbean & 25 & 16.2 \\
\hline Asian/Pacific Islander & 15 & 9.7 \\
\hline Native American/American Indian & 2 & 1.3 \\
\hline \multicolumn{3}{|l|}{ Marital Status } \\
\hline Single/Never Married & 43 & 27.9 \\
\hline Married/Living with partner & 69 & 44.8 \\
\hline Separated & 27 & 17.5 \\
\hline Divorced & 13 & 8.4 \\
\hline Widowed & 2 & 1.3 \\
\hline \multicolumn{3}{|l|}{ Highest Level of Education } \\
\hline MSW & 123 & 79.9 \\
\hline $\mathrm{PhD/DSW}$ & 31 & 20.1 \\
\hline \multicolumn{3}{|c|}{ Extra Hours Worked Per Week $(n=36)$} \\
\hline $0-5$ & 26 & 72.2 \\
\hline $6-10$ & 6 & 16.7 \\
\hline $11-15$ & 2 & 5.6 \\
\hline $16-20$ & 1 & 2.8 \\
\hline Greater than 20 & 1 & 2.8 \\
\hline \multicolumn{3}{|l|}{ Salary Range } \\
\hline$\$ 25,000$ or under & 1 & 0.6 \\
\hline$\$ 26,000-\$ 35,000$ & 23 & 14.9 \\
\hline$\$ 36,000-\$ 45,000$ & 30 & 19.5 \\
\hline
\end{tabular}




\begin{tabular}{|c|c|c|}
\hline$\$ 46,000-\$ 55,000$ & 37 & 24.0 \\
\hline$\$ 56,000-\$ 65,000$ & 33 & 21.4 \\
\hline$\$ 66,000-\$ 76,000$ & 15 & 9.7 \\
\hline$\$ 76,000$ or more & 15 & 9.7 \\
\hline \multicolumn{3}{|l|}{ Work Setting } \\
\hline Agency & 114 & 74.0 \\
\hline Private Practice & 40 & 26.0 \\
\hline \multicolumn{3}{|l|}{ Agency } \\
\hline Child Protective Services & 6 & 3.9 \\
\hline Hospital & 14 & 9.1 \\
\hline Aging & 13 & 8.4 \\
\hline School & 28 & 18.2 \\
\hline Substance Abuse Clinic & 19 & 12.3 \\
\hline Correctional Facility & 9 & 5.8 \\
\hline Mental Health & 47 & 30.5 \\
\hline Communal Agency & 13 & 8.4 \\
\hline Admin & 1 & 0.6 \\
\hline Admin/financial & 1 & 0.6 \\
\hline College Counseling & 1 & 0.6 \\
\hline Private Practice & 2 & 1.2 \\
\hline \multicolumn{3}{|l|}{ Type of Clients } \\
\hline Children & 41 & 26.6 \\
\hline Adolescents & 51 & 33.1 \\
\hline Adults & 62 & 40.3 \\
\hline \multicolumn{3}{|l|}{ Percent Trauma Work } \\
\hline None & 25 & 16.2 \\
\hline $25 \%$ or less & 41 & 26.6 \\
\hline $25 \%-50 \%$ & 38 & 24.7 \\
\hline $50 \%-75 \%$ & 38 & 24.7 \\
\hline $75-100 \%$ & 12 & 7.8 \\
\hline \multicolumn{3}{|l|}{ Practice Self-Care } \\
\hline No & 47 & 30.5 \\
\hline Yes & 107 & 69.5 \\
\hline \multicolumn{3}{|l|}{ Practice Yoga } \\
\hline No & 94 & 61.0 \\
\hline Yes & 60 & 39.0 \\
\hline \multicolumn{3}{|l|}{ Practice Meditation } \\
\hline No & 92 & 59.7 \\
\hline Yes & 62 & 40.3 \\
\hline
\end{tabular}


Table 3. Descriptive analysis of continuous study variables $(\mathrm{n}=154)$

\begin{tabular}{|l|l|l|l|}
\hline \multicolumn{1}{|c|}{ Variable } & \multicolumn{1}{|c|}{$\begin{array}{c}\text { Mean } \\
(\text { SD) }\end{array}$} & Min/Max & $\begin{array}{l}\text { Potential } \\
\text { Range }\end{array}$ \\
\hline $\begin{array}{l}\text { Months Practicing } \\
\text { Yoga }(\boldsymbol{n}=\mathbf{4 7})\end{array}$ & $\begin{array}{l}25.17 \\
(17.98)\end{array}$ & $4-73$ & NA \\
\hline $\begin{array}{l}\text { Months Practicing } \\
\text { Meditation }(\boldsymbol{n}=48)\end{array}$ & $\begin{array}{l}27.98 \\
(21.6)\end{array}$ & $2-120$ & NA \\
\hline Mindfulness & $2.88(.71)$ & $1.00-4.00$ & $1.00-4.00$ \\
\hline MSQ & $3.47(1.10)$ & $1.00-5.00$ & $1.00-5.00$ \\
\hline STSS & $1.93(.96)$ & $1.00-4.88$ & $1.00-5.00$ \\
\hline
\end{tabular}

Table 4. Correlation analysis examining the relationship between continuous study variables $(n=154)$

\begin{tabular}{|l|l|l|l|}
\hline Variables & $\mathbf{1}$ & $\mathbf{2}$ & $\mathbf{3}$ \\
\hline 1. Mindfulness & -- & $.80 * *$ & $-.54 * *$ \\
\hline 2. MSQ & -- & & $-.56 * *$ \\
\hline 3. STSS & & & -- \\
\hline \multicolumn{3}{|c|}{$* p<.05, * *<.01}$. \\
\hline
\end{tabular}

4.2.3 Hypothesis 1a: There is a positive correlation between the length of time practicing meditation and the workers' level of mindfulness. Table 9 reports that at the bivariate level that hypothesis 1a is not supported as time practicing meditation is not correlated with mindfulness at a statistically significant level $[\mathrm{r}(32)=.32, \mathrm{p}<.07]$.

4.2.4 Hypothesis $1 b$ : There is a positive correlation between the length of time practicing yoga and the workers' level of mindfulness. At the bivariate level, Table 9 reports that hypothesis $1 \mathrm{~b}$ is supported as time practicing yoga is correlated with mindfulness at a statistically significant level $[\mathrm{r}(45)=.46, \mathrm{p}<.01]$. Table 10 indicates that at the bivariate level, months of yoga practice was also significantly related to gender $[\mathrm{t}(48)=2.51, \mathrm{p}<.05]$ and the practice of self-care $[\mathrm{t}(45)=3.91, \mathrm{p}<.001]$. However, months of yoga practice was not significantly related to age $[\mathrm{F}(3$, $43)=.38, \mathrm{p}=.77]$, race $[\mathrm{F}(5,41)=1.82, \mathrm{p}=.13]$, education level $[\mathrm{t}(45)=.73, \mathrm{p}=.23]$, perceived trauma work $[\mathrm{F}(4,42)=1.60$, $\mathrm{p}=.19]$ and meditation practice $[\mathrm{t}(45)=.67, \mathrm{p}=.51]$.

Table 11 presents a multiple linear regression model, which achieved a level of statistical significance $[F(3,43)$ $=11.04, \mathrm{p}<.001, \mathrm{R}^{2}=.44$, Adjusted $\left.\mathrm{R}^{2}=.40\right]$. Male gender was significantly associated with higher levels of mindfulness $[\mathrm{B}=-.40, \mathrm{SE}=.12, \beta=-.37, \mathrm{p}<.05]$, as was reports of practicing self-care $[\mathrm{B}=.30, \mathrm{SE}=.12, \beta=.35, \mathrm{p}<.05]$. Lastly, number of months practicing yoga was significantly related to higher mindfulness scores in the context of the full multivariate model $[\mathrm{B}=.01, \mathrm{SE}=.10, \beta=.28, \mathrm{p}<.05]$.
Table 5. Bivariate analysis of MSQ and study variables $(\mathrm{n}=154)$

\begin{tabular}{|c|c|c|c|}
\hline Variable & M (SD) & $\mathbf{t} / \mathbf{F}(\mathbf{d f})$ & $\mathbf{p}$ \\
\hline \multicolumn{2}{|l|}{ Gender } & $.51(152)$ & .61 \\
\hline Male & $3.54(1.02)$ & & \\
\hline Female & $3.44(1.13)$ & & \\
\hline \multicolumn{2}{|l|}{ Age $^{1}$} & $\begin{array}{l}3.55(4, \\
149)\end{array}$ & .009 \\
\hline $20-25$ & $2.42(1.06)$ & & \\
\hline $26-30$ & $3.69(.97)$ & & \\
\hline $31-40$ & $3.44(1.04)$ & & \\
\hline $41-50$ & $3.66(1.13)$ & & \\
\hline 51 or over & $3.08(1.19)$ & & \\
\hline \multicolumn{2}{|l|}{ Race $^{2}$} & $\begin{array}{l}3.41(5, \\
148)\end{array}$ & .01 \\
\hline Caucasian & $3.80(.96)$ & & \\
\hline Black/African American & $3.09(1.25)$ & & \\
\hline Hispanic/Latino & $3.32(1.12)$ & & \\
\hline West Indian/Caribbean & $3.04(1.13)$ & & \\
\hline Asian/Pacific Islander & $4.03(.75)$ & & \\
\hline $\begin{array}{l}\text { Native } \\
\text { American/American } \\
\text { Indian }\end{array}$ & $4.00(.28)$ & & \\
\hline \multicolumn{2}{|l|}{ Education Level } & $\begin{array}{l}-1.89 \\
(60.48)\end{array}$ & .06 \\
\hline MSW & $3.40(1.14)$ & & \\
\hline $\mathrm{PhD/DSW}$ & $3.75(.85)$ & & \\
\hline \multicolumn{2}{|l|}{ Percent Trauma Work } & $\begin{array}{l}2.05(4, \\
149)\end{array}$ & .09 \\
\hline None & $3.04(1.00)$ & & \\
\hline $25 \%$ or less & $3.81(1.03)$ & & \\
\hline $25 \%-50 \%$ & $3.50(1.09)$ & & \\
\hline $50 \%-75 \%$ & $3.39(1.04)$ & & \\
\hline $75-100 \%$ & $3.37(1.51)$ & & \\
\hline \multicolumn{2}{|l|}{ Yoga Practice } & $\begin{array}{l}6.88 \\
(150.49) \\
\end{array}$ & .001 \\
\hline Yes & $4.08(.96)$ & & \\
\hline No & $3.08(.28)$ & & \\
\hline \multicolumn{2}{|l|}{ Meditation Practice } & $\begin{array}{l}8.12 \\
(149.14)\end{array}$ & .001 \\
\hline Yes & $4.15(.64)$ & & \\
\hline No & $3.01(1.11)$ & & \\
\hline
\end{tabular}


Table 6. Multiple regression analysis examining MSQ scores ( $\mathrm{n}=154)$

\begin{tabular}{|c|c|c|c|}
\hline Variable & B (SE) & $\boldsymbol{\beta}$ & p \\
\hline \multicolumn{4}{|l|}{ Age } \\
\hline 51 or over (Reference group) & & & \\
\hline $20-25$ & $.05(.27)$ & .01 & .85 \\
\hline $26-30$ & $.41(.27)$ & .17 & .03 \\
\hline $31-40$ & $.29(.18)$ & .12 & .11 \\
\hline $41-50$ & $.51(.19)$ & .20 & .007 \\
\hline Practice Yoga & $.26(.12)$ & .12 & .03 \\
\hline Mindfulness & $1.13(.09)$ & .73 & .001 \\
\hline
\end{tabular}

Table 7. Bivariate analysis of STSS and study variables $(n=154)$

\begin{tabular}{|c|c|c|c|}
\hline Variable & M (SD) & $\mathbf{t} / \mathbf{F}(\mathbf{d f})$ & p \\
\hline \multicolumn{2}{|l|}{ Gender } & $-.80(152)$ & .41 \\
\hline Male & $1.83(.99)$ & & \\
\hline Female & $1.97(.95)$ & & \\
\hline \multicolumn{2}{|l|}{ Age $^{1}$} & $3.76(4,149)$ & .006 \\
\hline $20-25$ & $2.95(1.13)$ & & \\
\hline $26-30$ & $1.79(.83)$ & & \\
\hline $31-40$ & $1.89(.93)$ & & \\
\hline $41-50$ & $1.76(.82)$ & & \\
\hline 51 or over & $2.23(1.22)$ & & \\
\hline \multicolumn{2}{|l|}{ Race } & $1.06(5,148)$ & .38 \\
\hline Caucasian & $1.74(.77)$ & & \\
\hline Black/African American & $2.10(1.24)$ & & \\
\hline Hispanic/Latino & $2.07(1.02)$ & & \\
\hline West Indian/Caribbean & $2.08(.97)$ & & \\
\hline Asian/Pacific Islander & $1.67(.84)$ & & \\
\hline Native American/American Indian & $1.97(.87)$ & & \\
\hline \multicolumn{2}{|l|}{ Education Level } & $.61(61.88)$ & .55 \\
\hline MSW & $1.95(1.01)$ & & \\
\hline $\mathrm{PhD/DSW}$ & $1.85(.73)$ & & \\
\hline \multicolumn{2}{|l|}{ Percent Trauma Work ${ }^{2}$} & $3.76(4,149)$ & .006 \\
\hline None & $1.60(.97)$ & & \\
\hline $25 \%$ or less & $1.68(.78)$ & & \\
\hline $25 \%-50 \%$ & $1.94(.88)$ & & \\
\hline $50 \%-75 \%$ & $2.25(.99)$ & & \\
\hline $75-100 \%$ & $2.47(1.21)$ & & \\
\hline \multicolumn{2}{|l|}{ Yoga Practice } & $-3.60(144.78)$ & .001 \\
\hline Yes & $1.64(1.64)$ & & \\
\hline No & $2.12(1.10)$ & & \\
\hline \multicolumn{2}{|l|}{ Meditation Practice } & $-4.72(142.35)$ & .001 \\
\hline Yes & $1.55(.55)$ & & \\
\hline No & $2.19(1.08)$ & & \\
\hline
\end{tabular}

${ }^{1}$ Post hoc analysis indicated the mean score for the 20-25 group was significantly higher than 26-30, 31-40, and 41-50 groups. ${ }^{2}$ Post hoc analysis indicated the mean scores did not differ significantly. 
Table 8. Multiple regression analysis examining STSS scores $(n=154)$

\begin{tabular}{|c|c|c|c|}
\hline \multirow{2}{*}{\begin{tabular}{l}
\multicolumn{1}{c}{ Variable } \\
Age \\
51 or over (Reference group) \\
$20-25$
\end{tabular}} & B (SE) & $\beta$ & p \\
\hline \multirow{2}{*}{\multicolumn{4}{|c|}{$\begin{array}{l}\text { Age } \\
51 \text { or over (Reference group) }\end{array}$}} \\
\hline & & & \\
\hline & $.30(.34)$ & .07 & .38 \\
\hline $26-30$ & $-.32(.23)$ & -.15 & .16 \\
\hline $31-40$ & $-.30(.23)$ & -.14 & .19 \\
\hline $41-50$ & $-.44(.23)$ & -.20 & .06 \\
\hline Practice Yoga & $-.04(.15)$ & -.02 & .80 \\
\hline Mindfulness & $-.66(.11)$ & -.49 & .001 \\
\hline
\end{tabular}

Table 9. Sug-group correlation analysis examining the relationship between mindfulness with number of months practising meditation and yoga

\begin{tabular}{|l|c|l|l|}
\hline \multicolumn{1}{|c|}{ Variables } & $\mathbf{1}$ & \multicolumn{1}{|c|}{$\mathbf{2}$} & \multicolumn{1}{|c|}{$\mathbf{3}$} \\
\hline 1. Mindfulness & -- & $.32(n=34)$ & $.46 * *(n=47)$ \\
\hline 2. Meditation months & & -- & $.75 * *$ \\
\hline 3. Yoga months & \multicolumn{2}{|l}{} & -- \\
\hline \multicolumn{2}{|c|}{$*<<.05, * * p<.01$} \\
\hline
\end{tabular}

Table 10. Bivariate analysis of mindfulness and study variables $(n=47)$

\begin{tabular}{|c|c|c|c|}
\hline Variable & M (SD) & $\mathrm{t} / \mathrm{F}(\mathrm{df})$ & $\mathbf{p}$ \\
\hline \multicolumn{2}{|l|}{ Gender } & $2.51(48)$ & .016 \\
\hline Male & $3.65(.34)$ & & \\
\hline Female & $3.27(.40)$ & & \\
\hline \multicolumn{2}{|l|}{ Age } & $.38(3,43)$ & .77 \\
\hline $26-30$ & $3.26(.35)$ & & \\
\hline $31-40$ & $3.43(.38)$ & & \\
\hline $41-50$ & $3.32(.47)$ & & \\
\hline 51 and over & $3.37(.60)$ & & \\
\hline \multicolumn{2}{|l|}{ Race } & $1.82(5,41)$ & .13 \\
\hline Caucasian & $3.41(.43)$ & & \\
\hline Black/African American & $3.35(.07)$ & & \\
\hline Hispanic/Latino & $3.37(.40)$ & & \\
\hline West Indian/Caribbean & $3.01(.35)$ & & \\
\hline Asian/Pacific Islander & $3.55(.39)$ & & \\
\hline Native American/American Indian & $2.95(.07)$ & & \\
\hline \multicolumn{2}{|l|}{ Education Level } & $.73(45)$ & .23 \\
\hline MSW & $3.37(.39)$ & & \\
\hline PhD/DSW & $3.28(.45)$ & & \\
\hline \multicolumn{2}{|l|}{ Percent Trauma Work } & $1.60(4,42)$ & .19 \\
\hline None & $3.60(.42)$ & & \\
\hline $25 \%$ or less & $3.54(.51)$ & & \\
\hline $25 \%-50 \%$ & $3.24(.38)$ & & \\
\hline $50 \%-75 \%$ & $3.26(.37)$ & & \\
\hline $75-100 \%$ & $3.17(.16)$ & & \\
\hline \multicolumn{2}{|l|}{ Practice Self-Care } & $3.91(45)$ & .001 \\
\hline Yes & $3.49(.38)$ & & \\
\hline No & $3.06(.32)$ & & \\
\hline \multicolumn{2}{|l|}{ Meditation Practice } & $.67(45)$ & .51 \\
\hline Yes & $3.36(.39)$ & & \\
\hline No & $3.26(.49)$ & & \\
\hline
\end{tabular}


Table 11. Multiple linear regression analysis examining mindfulness scores $(n=47)$

\begin{tabular}{|l|l|l|l|}
\hline Variable & $\mathrm{B}(\mathrm{SE})$ & $\beta$ & $\mathrm{p}$ \\
\hline Gender & $-.40(.12)$ & -.37 & .002 \\
\hline Practice Self-Care & $.30(.12)$ & .35 & .014 \\
\hline Yoga Months & $.01(.10)$ & .28 & .047 \\
\hline \multicolumn{4}{|l|}{ Model $=F(3,43)=11.04, p<.001, \mathrm{R}^{2}=.44$, Adjusted $\mathrm{R}^{2}=.40$} \\
\hline
\end{tabular}

\section{Discussion}

\subsection{Hypothesis 1}

The findings indicate that hypothesis 1 was supported. Correlational significance was observed between study participants' age, 51 and over and those between the ages 2630 , as they evidenced significantly higher job satisfaction scores. The findings also indicated that mindfulness and those who practice yoga also evidenced significantly higher job satisfaction scores. Measured at the bivariate level, job satisfaction was related to age, yoga practice, and meditation practice. In light of this, this study lends further support that a relationship exists between mindfulness and job satisfaction. To date, there is a growing body of literature documenting the effectiveness of mindfulness practice for social workers and mental health workers alike (Neff, 2003; Christopher and Maris, 2010; May and O'Donovan, 2007; Baer, 2006; Brown, Ryan, and Creswell, 2007; Holzel et al., 2011). Workers with higher levels of mindful attention are likely to be positively correlated with satisfaction at work.

Although the efficacy of mindfulness practice and job satisfaction is becoming established in literature, the understanding of its effectiveness in different situations is still underdeveloped. This study shows that age is a significant factor in job satisfaction, while at the bivariate level, job satisfaction was not significantly related to gender, education level, and amount of trauma work. In addition to the need for additional research in these areas, these latter findings may be a result in part due to the sample, most participants were women, and it is possible that men and women may respond differently, although no evidence for gender differences has been reported in past research.

\subsection{Hypothesis $1 a$}

The findings suggest that hypothesis $1 \mathrm{~A}$ was not supported. This result is consistent with previous research. May and O'Donovan (2007) found that participation in yoga practices and, to some extent, meditation practices, did not appear to enhance levels of mindfulness.

\subsection{Hypothesis $1 b$}

On the other hand, the findings suggest that hypothesis 1B was supported. Similarly to hypothesis $1 \mathrm{~A}$, this result is inconsistent to May and O'Donovan's (2007) findings, where researchers found that participation in yoga practices did not enhance levels of mindfulness. There may be few explanations why this study demonstrated a positive correlation between the length of time practicing yoga and the workers' level of mindfulness. First, the yoga practitioners may have an experiential background that allows them to integrate clinical feedback more immediately and effectively. In addition, the quality of practice time is potentially as relevant to outcomes as the quantity; this issue deserves consideration in future research.

\subsection{Recommendations for social work practice and education}

Building on the notion that exposure to STS places social workers at risk of burnout and psychological distress that comprises service outcomes and worker effectiveness (Bride, 2007). Since clinical evidence suggests that STS can be managed or prevented with a combination of personal, professional and administrative or policy interventions, an ethical duty exists to provide education of the prevalence and impact of STS on the worker (Rudolph et al., 1997). Implications for policy include a duty to inform and a duty to train. The results of this study may help aid in the prevention of STS and keeping the social worker workforce in providing quality services, which may support and inform policy initiative, program development, and education to sustain a resilient workforce.

\section{Conclusions}

The primary purpose of this study was to identify the relationship between mindfulness practice and job satisfaction, and the dependent variable of STS for social workers. This study found that higher levels of mindfulness are related to higher levels of job satisfaction and lower levels of STS, for social workers. This new knowledge may help indicate future trends in research, investigating the varied demographic variables and quality of mindfulness practice as it pertains to STS. As supported by the findings of this study, mindfulness practice, as an adjunct to social worker self-care practices, can help social workers be more present, accepting and effective in their relationship with clients. 


\section{Limitations of the study}

The potential limitations include self-report nature, mindfulness and STS measures, and the correlational study design. A weakness of the self-report nature is that respondents to questionnaires and mailed surveys have a lower response rate than in person interviews (Patton, 2000). Also, both the mindfulness and STS measures used in this study may be considered as limitations. To measure mindfulness, instruments are still in their infancy; the mindfulness instrument in this study measures centered attention and does not provide a comprehensive multidimensional analysis of one's state of mindfulness. Furthermore, the STS measure lacks the context in which the traumatic stress was experienced (May and O'Donovan, 2007).

The limitations of a correlational design are the possibility of reverse causality and confounding variable(s). Reverse causality is a problem that occurs when the direction of causality between two factors can be either direction. This can occur because the direction of causality for two factors, A and $\mathrm{B}$, cannot be determined, thus, changes in factor A can cause changes in factor $\mathrm{B}$ or vice versa. Confounding variable is an unanticipated variable not accounted for in the list of measured variables and can be causing changes in the measured variables (Privitera, 2013).

\section{References}

Abendroth, M. and Flannery, J. (2006) 'Predicting the Risk of Compassion Fatigue: A Study of Hospice Nurses', Journal of Hospice \& Palliative Nursing, 8(6), pp.346-356.

American Psychiatric Association. (2000). Diagnostic and Statistical Manual of Mental Disorders. 4th edn. Washington, DC: American Psychiatric Association.

Astin, J. (1997) 'Stress Reduction through Mindfulness Meditation', Psychotherapy and Psychosomatics, 2(66), pp.97-106.

Baer, R. A. (2006) 'Mindfulness Training as a Clinical Intervention: A Conceptual and Empirical Review', Clinical Psychology: Science and Practice, 10(2), pp.125-143.

Baker, E. (2003) Caring for Ourselves as Psychologists. American Psychological Association. Available at: http://www.epsychologist.org/index.iml?mdl=exam/show_art icle.mdl\&Material_ID=1 (Accessed: 5 December 2019)

Benson, H. (1975) The Relaxation Response. New York, NY: William Morrow.

Bober, T. and Regehr, C. (2006) 'Strategies for Reducing Secondary or Vicarious Trauma: Do They Work?', Brief Treatment and Crisis Intervention, 6(1), pp.1-9.
Boyce, B. (2011) The Mindfulness Revolution. Boston, MA: Shambhala.

Breslau, N., Davis, G., Peterson, E. and Schultz, L. (1997) 'Psychiatric Sequelae of Posttraumatic Stress Disorder in Women', Archives of General Psychiatry, 54(1), pp.81-87.

Bride, B. (2004) 'Development and Validation of the Secondary Traumatic Stress Scale', Research on Social Work Practice, 14(1), pp.27-35.

Bride, B. (2007) 'Prevalence of Secondary Traumatic Stress among Social Workers', Social Work, 52(1), pp.63-70.

Brown, K. W., Ryan, R. M. and Creswell, J. D. (2007) 'Mindfulness: Theoretical Foundations and Evidence for its Salutary Effects', Psychological Inquiry, 18(4), pp.211-237.

Christopher, J. C. and Maris, J. A. (2010) 'Integrating Mindfulness as Self-Care into Counseling and Psychotherapy Training', Counselling and Psychotherapy Research, 10(2), pp.114-125.

Collins, L. (2003) 'Working with the Psychological Effects of Trauma: Consequences for Mental Health Care Workers a Literature Review', Journal of Psychiatric and Mental Health Nursing, 10(4), pp.417-424.

Cornille, T. A. and Meyers, T. W. (1999) 'Secondary Traumatic Stress Among Child Protective Service Workers: Prevalence, Severity and Predictive Factors', Traumatology, 5(1), pp.15-31.

Davidson, R. J., Kabat-Zinn, J., Schumacher, J., Muller, D. and Santorelli, S. (2003) 'Alterations in Brain and Immune Function Produced by Mindfulness Meditation', Psychosomatic Medicine, 65(4), pp.564-570.

Davidson, J. and Smith, R. (1990) 'Traumatic experiences in psychiatric outpatients', Journal of Traumatic Stress, 3(3), pp.459-475.

Dominguez-Gomez, E. and Rutledge, D. (2009) 'Prevalence of Secondary Traumatic Stress Among Emergency Nurses', Journal of Emergency Nursing, 35(3), pp.199-204.

Escalona, R., Tupler, L. A., Saur, C. D., Krishnan, K. R. R. and Davidson, J. R. (1997) 'Screening for Trauma History on an Inpatient Affective-Disorders Unit: A Pilot Study', Journal of Traumatic Stress, 10(2), pp.299-305.

Fang, C. Y., Reibel, D. K., Longacre, M. L., Rosenzweig, S., Campbell, D. E. and Douglas, S. D. (2010) 'Enhanced Psychosocial Well-Being Following Participation in a Mindfulness-Based Stress Reduction Program is Associated with Increased Natural Killer Cell Activity', The Journal of Alternative and Complementary Medicine, 16(5), pp.531538.

Feldman, G., Hayes, A., Kumar, S., Greeson, J. and Laurenceau, J.-P. (2007) 'Mindfulness and Emotion Regulation: The Development and Initial Validation of the Cognitive and Affective Mindfulness Scale-Revised (CAMS- 
R)', Journal of Psychopathology and Behavioral Assessment, 29(3), pp.177-190.

Figley, C. (2002) 'Compassion Fatigue: Psychotherapists' Chronic Lack of Self-care', Journal of Clinical Psychology, 58(11), pp.1433-1441.

Figley, C. (1993) 'Compassion Stress and The Family Therapist', Family Therapy News, (3), pp.1-8.

Figley, C. (1995) Compassion Fatigue: Coping with Secondary Traumatic Stress Disorder in Those Who Treat the Traumatized. $1_{\mathrm{st}}$ edn. London, UK: Routledge.

Guy, J. D., Poelstra, P. L. and Stark, M. J. (1989) 'Personal Distress and Therapeutic Effectiveness: National Survey of Psychologists Practicing Psychotherapy', Professional Psychology: Research and Practice, 20(1), pp.48-50.

Holzel, B. K., Lazar, S. W., Gard, T., Schuman-Olivier, Z., Vago, D. R. and Ott, U. (2011) 'How Does Mindfulness Meditation Work? Proposing Mechanisms of Action from a Conceptual and Neural Perspective', Perspectives on Psychological Science, 6(6), pp.537-559.

Kabat-Zinn, J. (2006) 'Mindfulness-Based Interventions in Context: Past, Present, and Future', Clinical Psychology: Science and Practice, 10(2), pp.144-156.

Kabat-Zinn, J., Massion, A. O., Kristeller, J., Peterson, L. G., Fletcher, K. E. and Pbert, L. (1992) 'Effectiveness of a Meditation-Based Stress Reduction Program in the Treatment of Anxiety Disorders', American Journal of Psychiatry, 149(7), pp.936-943.

Kabat-Zinn, J., Wheeler, E., Light, T., Skillings, A., Scharf, M. J., Cropley, T. G. and Bernhard, J. D. (1998) 'Influence of a Mindfulness Meditation-Based Stress Reduction Intervention on Rates of Skin Clearing in Patients with Moderate to Severe Psoriasis Undergoing Photo Therapy (UVB) and Photochemotherapy (PUVA)', Psychosomatic Medicine, 60(5), pp.625-632.

Kuyken, W., Peters, E., Power, M. J. and Lavender, T. (2003) 'Trainee Clinical Psychologists' Adaptation and Professional Functioning: A Longitudinal Study', Clinical Psychology \& Psychotherapy, 10(1), pp.41-54.

Lambert, M. J. and Barley, D. E. (2001) 'Research Summary on the Therapeutic Relationship and Psychotherapy Outcome', Psychotherapy: Theory, Research, Practice, Training, 38(4), pp.357-361.

Mann, S. (2004) “"People-Work": Emotion Management, Stress and Coping', British Journal of Guidance \& Counselling, 32(2), pp.205-221.

May, S. and O'Donovan, A. (2007) 'The Advantages of the Mindful Therapist', Psychotherapy in Australia, 13(4), pp.46 53.

Meldrum, L., King, R. and Spooner, D. (2002) Compassion Fatigue in Community Mental Health Case Managers. New York, NY: Brunner/Rutledge.
Neff, K. D. (2003) 'The Development and Validation of a Scale to Measure Self-Compassion', Self and Identity, 2(3), pp.223-250.

Newell, J. M. and MacNeil, G. A. (2010) 'Professional Burnout, Vicarious Trauma, Secondary Traumatic Stress, and Compassion Fatigue', Best Practices in Mental Health, 6(2), pp.57-68.

Park, E., Traeger, L., Vranceanu, A.-M., Scult, M., Lerner, J., Benson, H. and Fricchione, G. (2013) 'The Development of a Patient-Centered Program Based on the Relaxation Response: The Relaxation Response Resiliency Program (3RP)', Psychosomatics, 54(2), pp.165-174.

Patton, M. L. (2000) Proposing Empirical Research. Los Angeles, CA: Pryrczak Publishing.

Pearlman, L. A. and Saakvitne, K. (1995) Trauma and the Therapist: Countertransference and Vicarious Traumatization in Psychotherapy with Incest Survivors. 1st edn. New York, NY: W. W. Norton \& Company.

Privitera, G. (2013) Research Methods for the Behavioral Sciences. 1st edn. New York, NY: SAGE Publications.

Radley, M. and Figley, C. (2007) 'The Social Psychology of Compassion', Clinical Social Work Journal, 35(3), pp.207214.

Rubin, J. B. (1999) 'Close Encounters of a New Kind: Toward an Integration of Psychoanalysis and Buddhism', The American Journal of Psychoanalysis, 59(1), pp.5-24.

Rudolph, J. M., Stamm, B. H. and Stamm, H. E. (1997, November) Compassion Fatigue a Concerrn For Mental Health Policy, Providers, and Administration. Montreal, PQ, CA.

Shapiro, S. L., Carlson, L. E., Astin, J. A. and Freedman, B. (2006) 'Mechanisms of Mindfulness', Journal of Clinical Psychology, 62(3), pp.373-386.

Shapiro, S. L. and Walsh, R. (2003) 'An Analysis of Recent Meditation Research and Suggestions for Future Directions', The Humanistic Psychologist, 31(2-3), pp.86-114.

Shapiro, S., Shapiro, D. and Schwartz, G. (2000) 'Stress Management in Medical Education: A Review of the Literature', Academic Medicine, 75(7), pp.748-759.

Showalter, S. E. (2010) 'Compassion Fatigue: What Is It? Why Does It Matter? Recognizing the Symptoms, Acknowledging the Impact, Developing the Tools to Prevent Compassion Fatigue, and Strengthen the Professional Already Suffering from the Effects', American Journal of Hospice and Palliative Medicine, 27(4), pp.239-242.

Simpson, L. R. and Starkey, D. S. (2006) Secondary Traumatic Stress, Compassion Fatigue and Counselor Spirituality: Implications for Counselors Working with Trauma. Available at: http://www.counseling.org/resources/library/Selected\%20To pics/Crisis/Simpson.htm (Accessed: 2 November 2019). 
Sprang, G., Clark, J. J. and Whitt-Woosley, A. (2007) 'Compassion Fatigue, Compassion Satisfaction, and Burnout: Factors Impacting a Professional's Quality of Life', Journal of Loss and Trauma, 12(3), pp.259-280.

Stein, M. B., Walker, J. R., Hazen, A. L. and Forde, D. R. (1997) 'Full and Partial Posttraumatic Stress Disorder: Findings from a Community Survey', American Journal of Psychiatry, 154(8), pp.1114-1119.

Switzer, G. E., Dew, M. A., Thompson, K., Goycoolea, J. M., Derricott, T. and Mullins, S. D. (1999) 'Posttraumatic Stress Disorder and Service Utilization Among Urban Mental Health Center Clients', Journal of Traumatic Stress, 12(1), pp. 25-39.

Tabachnick, B. and Fidell, L. (2012) Using Multivariate Statistics. 6th edn. New York, NY: Pearson.

Turner, K. (2009) 'Mindfulness: The Present Moment in Clinical Social Work', Clinical Social Work Journal, 37(2), pp.95-103.

Tyssen, R., Vaglum, P., Grønvold, N. T. and Ekeberg, Ø. (2001) 'Factors in Medical School That Predict Postgraduate Mental Health Problems in Need of Treatment. A Nationwide and Longitudinal Study', Medical Education, 35(2), pp.110-120.

Va, B. (2001) 'Posttraumatic Stress Disorder in the National Comorbidity Survey', The Science of Mental Health: Fear and Anxiety, 52(12), pp.1048-1060.

Walsh, R. and Shapiro, S. L. (2006) 'The Meeting of Meditative Disciplines and Western Psychology: A Mutually Enriching Dialogue', American Psychologist, 61(3), pp.227239.

Weiss, L. (2004) Therapist's Guide to Self-Care. New York, NY: Brunner- Routledge.

Weiss, D., Davis, R., England, G. and Lofquist, L. (1967) Minnesota Satisfaction Questionnaire. Minnesota Studies in Vocational Rehabilitation. Minneapolis, MN: University of Minnesota. 